Jurnal Ilmu Keolahragaan Volume II Nomor 2 Oktober 2019

Sugiyanto

Tersedia di: http://jurnal.untan.ac.id/index.php/jilo

\title{
TES KEMAMPUAN LEMPAR TANGKAP DAN KETEPATAN UNTUK SISWA SEKOLAH DASAR
}

\author{
Sugiyanto \\ SD Negeri Kertosono, Kec Banyuurip, Purworejo, JATENG \\ Email: antoktjg@yahoo.co.id
}

\begin{abstract}
Abstrak
Tujuan penelitian ini untuk memvalidasi tes kemampuan lempar tangkap dan ketepatan bagi siswa sekolah dasar. Metode penelitian dengan melakukan uji coba lapangan terhadap desain tes lempar tangkap dan ketepatan melempar bagi kepentingan evaluasi pembelajaran di sekolah dasar. Sampel penelitian adalah siswa sekolah dasar 39 siswa. Setiap siswa melakukan uji coba tes 2 kali percobaan. Analisis valididtas dengan korelasi Peorson dan reliabilitas dengan Cronbach's Alpha. Berdasarkan analisis data diperoleh nilai validitas tes lempar tangkap adalah 0.818, ketepatan 0,832. Reliabilitas dengan menggunakan Alpha Cronbach dengan nilai lempar tangkap 0.956, ketepatan 0,729. Sehingga tes ini dapat dipergunakan untuk mengetes kemampuan melempar dan ketepatan.
\end{abstract}

Kata kunci: kemampuan lempar tangkap, tes ketepatan melempar. 


\section{Jurnal Ilmu Keolahragaan Volume II Nomor 2 Oktober 2019 \\ Sugiyanto \\ Tersedia di: http://jurnal.untan.ac.id/index.php/jilo}

\section{PENDAHULUAN}

Pendidikan jasmani merupakan salah satu komponen dalam pendidikan secara keseluruhan. Materi pendidikan jasmani secara teoritis mengacu pada teori movement education, baik itu Graham (2007) Gallahue (1982). Dalam konsep yang ditawarkan pendidikan jasmani memiliki tingkatan tingkatan yang perlu dilakukan agar siswa mampu mengikuti pembelajaran.

Penguasaan keterampilan gerak dalam setiap fase membutuhkan dorongan dan rangsangan dari orang dewasa (dalam kontek ini guru). PBM gerak dalam pendidikan jasmani siswa diharuskan memiliki pengalaman yang cukup agar menyenangi gerak. Ketika siswa senang terhadap gerak maka perlu diberikan kesempatan yang cukup dan memiliki pengalaman berhasil dalan fase perkembangan belajar gerak.

Kurangnya penguasaan siswa terhadap keterampilan gerak dasar dapat mempengaruhi terhadap penguasaan keterampilan teknik dasar yang akan menuju pada spesifik kecabangan olahraga. Penguasaan teknik dasar ini berbeda kebutuhannya untuk setiap kecabangan olahraga. Kemampuan melempar pada tenis akan berbeda dengan kemampuan teknik dasar melempar dalam sepak bola, softball baseball, ataupun lempar lembing.

Gerak diartikan sebagai hasil respon. Gerak motorik yang baru bagi anak memerlukan pengulangan-pengalanan dan bantuan orang lain, pengulangan itu merupakan bagian dari belajar. Setiap pengulangan dalam keterampilan baru memerlukan konsentrasi untuk melatih koneksitas dan koordinasi gerak dengan indera lainnya (Papalia, 2009: 144). Sinclar dalam kruger mengungkapkan merupakan keakuratan memproses informasi yang ke seseorang dalam merasakan anggota badannya. Konsep gerak yang dikemukakan oleh Laban yang diikuti Galllahue (1982), Carl, Elixabeth and Susan (1987), dan (Graham (2007), ada 4: (1) Body awareness (what can body do?) (1) spatial awareness ( where does body move?) (3) Qualities of movement (how does body mover?) (4) Relationship (whit whom or what does the body moves?), Gallahue (1982: 332) persepsi motorik terdiri atas body awareness, spatial awareness, direction awareness, temporal awareness.

Transfer keterampilan motorik dasar (overhead throw) dengan kecabangan olahraga ketika anak dapat melempar maka ada kemungkinan anak dapat belajar dengan cepat kecabangan seperti softball, volleyball, badminton netball, lempar lembing, tenis. (Jeff Walkley: 1998: 1).

Gambar.1, merupakan gerak dara Kemampuan gerak yang harus dikembangkan untuk mengembangkan keterampilan olahraga (Gallahue, 1982: 250). Salah satu keterampilan gerak dasar yang penting adalah kemampuan lempar tangkap dan kemampuan ketepatan dalam melempar. Kedua keterampilan ini memiliki fungsi yang sama dalam permainan permainan yang menggunakan tangan. Berdarkan klasifikasinya keterampilan lempar tangkap ini masuk kategori keterampilan manipulasi. Ketika mampu melakukan lempar tangkap statis dan dikembangkan menjadi dinamis maka akan memiliki transfer belajar pada bebarapa kecabangan dalam olahraga.

Ketika siswa dalam proses belajar mengajar, untuk kepentingan evaluasi pembelajaran diperlukan tes yang cocok berdasarkan karakteristik siswa. Tes keterampilan lembar tangkap selama ini adalah tes dengan melakukan lempar tangkap dengan bola tenis. Tes ini cenderung pasif dan aplikasi hasil penguasaan tes dalam permainan sangat rendah. Sehingga dalam penelitian ini 


\section{Jurnal Ilmu Keolahragaan Volume II Nomor 2 Oktober 2019 \\ Sugiyanto \\ Tersedia di: http://jurnal.untan.ac.id/index.php/jilo}

dilakukan penyusuna tes dan uji coba tes untuk divalidasi lapangan dan diketahui valisitas dan reliabilitas tes.

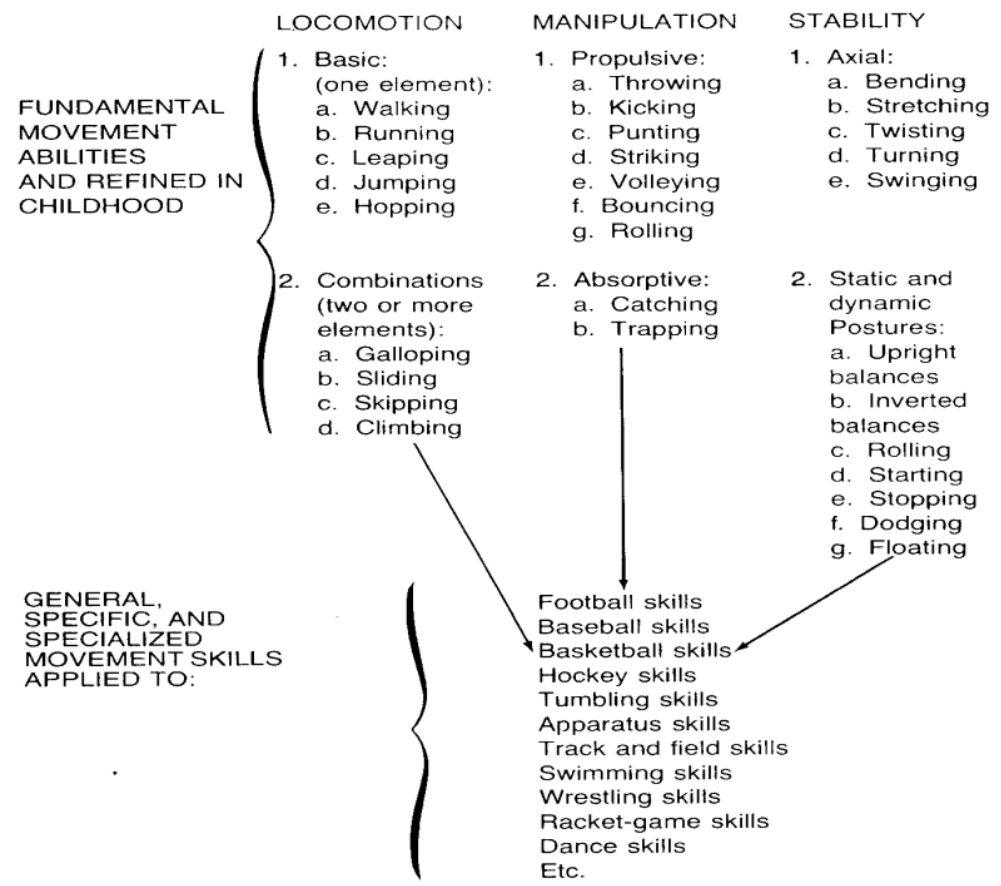

Gambar 1. Transfer Gerak Dasar ke Kecabangan Olahraga

\section{METODE}

Penelitian ini merupakan penelitian untuk menghasilkan tes untuk kepentingan evaluasi keterampilan lempar tangkap dan ketepatan melempar bagi siswa sekolah dasar. Tes yang disusun mempertimbangkan keefektifan transfer hasil tes dalam permainan, sehingga baik peralatan atapun jarak yang di tes kan telah dipertimbangkan dengan kemudahan dan kebermanfaatan dalam penilaitan kemampuan gerak yang di tes. Sehingga tes yang disusun berdasarkan dalam penelitian ini dibatasi hanya pada tes kemampuanlempar tangkap dan Tes kemampuan ketepatan melempar. Berdasarkan pada analisis di atas kemudian disusun serangkaian tes. Adapun operasional instrument yang dikembangkan dan diujicobakan adalah sebagai berikut:
Instrumen Tes Keterampilan Dasar

Tes Lempar Tangkap

Lapangan

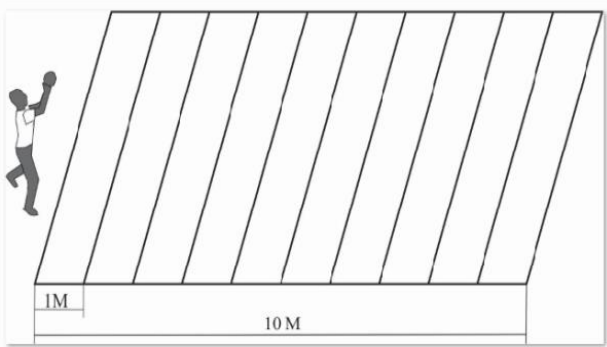

Gambar 2: Tes Melakukan Lempar Tangkap

Lapangan berukuran 5 x 10 meter, dan panjang lapangan dibagi menjadi 10 bagian dengan pembagian lebar yang sama (1m) Melempar bola dengan cara apapun 


\section{Jurnal Ilmu Keolahragaan Volume II Nomor 2 Oktober 2019 \\ Sugiyanto \\ Tersedia di: http://jurnal.untan.ac.id/index.php/jilo}

Cara melempar

Siswa memiliki hak 1 kali percobaan dengan menggunakan tangan kanan dan kiri

Siswa melakukan lemparan tiga kali dengan cara apapun

Bola kemudian ditangkap sendiri oleh pelempar

Pensekoran

Ukuran keberhasilan diukur dari ujung kaki depan ketika melakukan lemparan dan ujung kaki belakang ketika menangkap bola.

Tes Ketepatan Melempar

Jarak pelempar dengan target $5 \mathrm{~m}$

Target daerah dengan ukuran diameter 40

dengan skor 3,2,1

3 tepat di tengah posisi tengah

2 pada lingkar kedua

1 pada ruang lingkaran terluar

Dengan perhitungan rerata.

Cara pelaksanaan

Siswa berdiri di belakang garis lemparan

Melakukan lemparan dengan cara apapune arah sasaran

Memiliki hak untuk melempar 3 kali kanan

Memiliki kesempatan mencoba satu kali

Pensekoran

Skor dinilai dengan ketepatan bola mengenai target

Lapangan

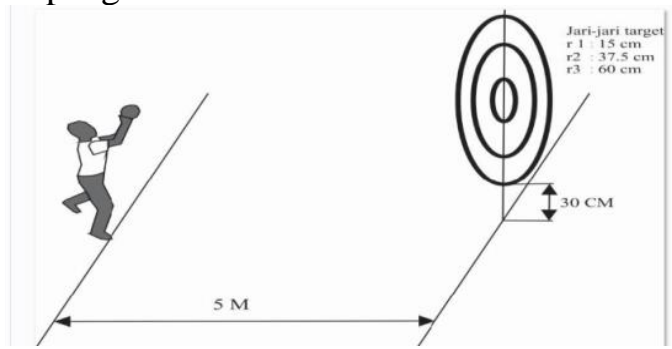

Gambar 3: Tes Ketepatan Melempar

Validasi tes

Siswa kelas 3 sampai kelas 5 sekolah dasar dipergunakan sebagai sampel uji coba terhadap keterampilan dasar yang telah disusun. Setiap orang coba memiliki kesempatan untuk melakukan percobaan 1 kali percobaan kemudian tes dilaksanakan.

Reliabilitas

Instrument disusun atas dasar analisis kebutuhan gerak yang diperlukan untuk mendukung kebutuhan bermain kick ball. Perhitungan validitas dengan menggunakan korelasi dari Pearson dan relabilitas dengan Cronbach Alpha.

\section{HASIL}

Uji coba telah dilaksanakan dengan menggunakan siswa sekolah dasar dengan hasil validitas korelasi kemampuan Lempar tangkap 0.818, ketepatan 0,832. Reliabilitas dengan menggunakan Alpha Cronbach dengan nilai lempar tangkap 0.956, ketepatan 0,729. Berdasarkan hasil uji coba lapangan dapat dinyatakan bahwa serangkaian tes kemampuan gerak dasar dinyatakan valid dan reliable untuk mengukur keterampilan gerak dasar. Hasil lengkap disajikan pada tabel 1 hingga tabel 4.

Tabel 1: Lempar Tangkap Lempar tangkap_I I_bawah

\begin{tabular}{ccc}
$\begin{array}{c}\text { Lempar } \\
\text { tangkap_ } \\
\text { I_bawah }\end{array}$ & $\begin{array}{c}\text { Pearson } \\
\text { Correlation }\end{array}$ & $.818^{* *}$ \\
& $\begin{array}{c}\text { Sig. (2- } \\
\text { tailed) }\end{array}$ & .002 \\
\cline { 2 - 3 } & $\mathrm{N}$ & 11 \\
\hline
\end{tabular}

*. Correlation is significant at the 0.05 level (2-tailed).

Tabel 2: Hasil Analisis Validitas Ketepatan

\begin{tabular}{ccc}
\hline & & $\begin{array}{c}\text { ketept_II_at } \\
\text { as }\end{array}$ \\
\hline ketept_I_b & & \\
awah & $\begin{array}{c}\text { Pearson } \\
\text { Correlation }\end{array}$ & $.832^{* *}$ \\
& Sig. (2-tailed) & .001 \\
\cline { 2 - 3 } & $\mathrm{N}$ & 11 \\
\hline *. Correlation is significant at the 0.05 level (2- \\
tailed).
\end{tabular}




\section{Jurnal Ilmu Keolahragaan Volume II Nomor 2 Oktober 2019 \\ Sugiyanto \\ Tersedia di: http://jurnal.untan.ac.id/index.php/jilo}

Tabel 3: Hasil Uji Reliabilitas Tes Keterampilan Gerak Dasar Lempar Tangkap

\begin{tabular}{cc}
\hline \multicolumn{2}{c}{ Reliability Statistics } \\
\hline Cronbach's Alpha & $\begin{array}{c}\text { N of } \\
\text { Items }\end{array}$ \\
\hline .956 & 2 \\
\hline
\end{tabular}

\begin{tabular}{|c|c|}
\hline \multicolumn{2}{|c|}{$\begin{array}{c}\text { Tabel .4.Hasil Uji Reliabilitas Tes } \\
\text { Keterampilan Gerak Ketepatan } \\
\text { Reliability Statistics }\end{array}$} \\
\hline Cronbach's Alpha & $\mathrm{N}$ of \\
\hline .729 & 2 \\
\hline
\end{tabular}

\section{PEMBAHASAN}

Hasil temuan menunjukkan bahwa instrument yang disusun valid dan reliable untuk mengukur kemampuan gerak dasar melempar, menangkap serta ketepatan. Berdasarkan hasil ini maka ketika siswa teridentifikasi telah memiliki kemampuan melempar, menangkap harapannya dapat bermain permainan yang berkaitan dengan melempar dan menangkap. Hasil dari tes ini

Lebih lanjut dikatakan oleh peneliti lain Still, measuring game performance by assessing the actions taken by players in response to various game situations is clouded by whether the players correctly execute what they decide to do in response to the game situation that confronts them (Blomqvist et al., 2000). Often children know what to do, but are not able to do it, due to insufficient skill (Blomqvist et al., 2001). Kedua penyataan ini "sebenarnya mengetahui apa yang harus dilakukan?" tetapi tidak dapat melakukan dan gerak masih kurang efisien, bukan hanya terjadi pada anak. Hal ini terjadi pada orang dewasa ketika dalam situasi permainan. Pemain memilih gerak dasar yang tepat atau teknik dasar yang tepat dan cepat serta efisien memerlukan tingkat penguasaan gerak dasar yang baik, yang nantinya gerak merupakan bentuk sederhana. Hal ini dibutuhkan karena kemampuan gerak dasar anak tidak sama. Ketika diketahui kemampuan gerak dasar dengan pasti, maka untuk proses pembelajaran atupun latihan akan lebih mudah demi kepentingan pengelompokan.

Mengutip pernyataan Thomas et al. (1994), we distinguished in this study between the quality of decision-making in a game situation and the actual execution of motor skills during game performance, although both determine successful game performance. Pernyataan ini memberikan gambaran bahwa pengambilan keputusan dalam situasi beramian dalam hal penggunaan keterampilan gerak menentukan kesuksesan dalam permainan. Ketika jenis ketermpilan yang dipilih dan dilakukan adalah tepat dan benar dengan kualias yang baik, maka akan mendukung terhadap kesuksesan dalam permainan yang dimainkan

dasar ini akan ditingkatkan menjadi teknik sesuai dengan kebutuhan dalam permainan.

Namum demikian keterampilan gerak dasar hanyalah salah satu dasar dalam upaya agar anak dapat berpartisipasi dalam permainan. Masih diperlukan lagi keterampilan lain yang sangat diperlukan seperti diungkapkan beberapa ahli sebagai berikut, (McPherson, 1994; Thomas, French, \& Humphries, 1986) have stressed the importance of multiple measures of cognitive and skill performance. Seperti diungkapan di atas diperlukan pengukuran terhadap banyak keterampilan, beberapa diantaranya keterampilan kognitif dan keterampilan menunjukkan skill dalam permainan. Hal ini lebih mengacu pada menanggapi situasi dalam permainan yang sesungguhnya dalam waktu yang singkat harus 


\section{Jurnal Ilmu Keolahragaan Volume II Nomor 2 Oktober 2019 \\ Sugiyanto \\ Tersedia di: http://jurnal.untan.ac.id/index.php/jilo}

bereaksi dengan benar. Berbeda degan tes yang peneliti lakukan. Anak diberitahu, diberi kesempatan mencoba dengan adanya contoh terlebih dahulu, dalam sitausi yang tenang dan hanya terfokus pada item apa yang sedang di teskan.

\section{KESIMPULA N}

Tes yang telah disusun dapat dipergunakan untuk melihat kemampuan gerak dasar, kaitannya dengan modal dasar untuk kepentingan evaluasi dalam pembelajaran, juga dapat dipergunakan sebagai prediksi keterampilan bermain kecabangan yang kitannya dengan koordinasi mata dan tangan. Harapannya ketika siswa menguasai gerak dasar minimal maka dipastikan sudah dapat berpartisipasi bermain dalam permainan ini.

\section{DAFTAR PUSTAKA}

Blomqvist, M., Luhtanen, P., Laakso, L. (2001) Comparison of two types of instruction in badminton. European journal of physical education, 6, 139155.

Blomqvist, M.T., Luhtanen, P., Laakso L., Keskinen, E. (2000) Validation of a video-based game-understanding test procedure in badminton. Journal of teaching in physical education, 19, 325-337.

Carl, Elixabeth and Susan. (1987). Physical education for children. New Jersey. Prentice-Hall.

Gallahue D, (1982). Developmental

Movement Experience for Childrent. Canada. John Wiley \& Sons.
Gallahue D, (1982). Understanding Motor Development Childrent. Canada.John Wiley \& Sons.

Gallahue \& Ozmun. (1998). Understading Motor Development. A devision of the McGraw-Hil company. Singapore.

Graham G, Shirley Ann/Hale, Melisa Pr. (2007). Children Moving. New York. McGraw-Hill Gréhaigne, J.-F., Godbout, P., \& Bouthier, D. (1997) Performance assessment in team sports. Journal of teaching in physical education, 16, 500-516.

Jeffry Walkley. (1998). Fundamental Motor Skills an Activities Resourse for Classroom Teachers. Departement of Education. Fictoria. Australia.

Jeffry Walkley. (1998). An activities Resource for Classroom Teachers. Departemen of Education. Victoria.

McPherson, S.L. (1994) The development of sport expertise: Mapping the tactical domain. Quest, 46, 223-240.

Papalia. Olds. Teldman (Brian manswendy; Penerjemah). (2009). Judul asli; Human Development. Terjemahan: Perkembangan Manusia. Salemba Humanika. Salemba.

Thomas, K.T., \& Thomas, J.R. (1994). Developing expertise in sport: The relation of knowledge and performance. International journal of sport psychology, 25, 295-312.

Thomas, J.R., French, K.E., Humphries, C.A. (1986) Knowledge development and sport skill performance: directions in motor behavior research. Journal of sport psychology, 8, 259-272. 